\title{
Taxonomic bias and international biodiversity conservation research
}

\author{
Michael R. Donaldson $^{a b \star}$, Nicholas J. Burnett ${ }^{\text {bc }}$, Douglas C. Braun ${ }^{c}$, Cory D. Suski ${ }^{a}$, Scott G. Hinch ${ }^{c}$, \\ Steven J. Cooke ${ }^{\mathrm{b}}$, and Jeremy T. Kerr ${ }^{\mathrm{d}}$ \\ a Department of Natural Resources and Environmental Sciences, University of Illinois at Urbana-

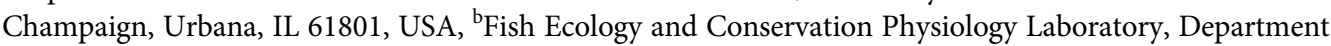 \\ of Biology and Institute of Environmental Science, Carleton University, Ottawa, ON K1S 5B6, Canada, \\ 'Pacific Salmon Ecology and Conservation Laboratory, Department of Forest and Conservation Sciences, \\ University of British Columbia, Vancouver, BC V6T 1Z4, Canada, ${ }^{\mathrm{d} C a n a d i a n ~ F a c i l i t y ~ f o r ~ E c o i n f o r m a t i c s ~}$ \\ Research, University of Ottawa, Ottawa, ON K1N 6N5, Canada
}

*michael.r.donaldson@gmail.com

\section{OPEN ACCESS}

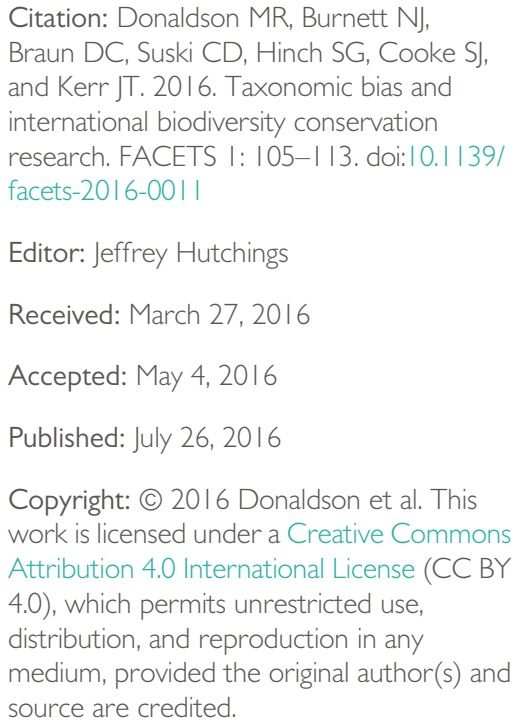

Published by: Canadian Science Publishing

\section{Abstract}

While greater research on threatened species alone cannot ensure their protection, understanding taxonomic bias may be helpful to address knowledge gaps in order to identify research directions and inform policy. Using data for over 10000 animal species listed on the International Union for Conservation of Nature Red List, we investigated taxonomic and geographic biodiversity conservation research trends worldwide. We found extreme bias in conservation research effort on threatened vertebrates compared with lesser-studied invertebrates in both terrestrial and aquatic habitats at a global scale. Based on an analysis of common threats affecting vertebrates and invertebrates, we suggest a path forward for narrowing the research gap between threatened vertebrates and invertebrates.

Key words: research bias, Convention on Biological Diversity, endangered, threatened, vulnerable, IUCN

\section{Introduction}

International biodiversity conservation strategies, such as the United Nations Convention on Biological Diversity (CBD), as well as an increasing number of national and regional biodiversity policies, aim to reduce biodiversity loss and protect at-risk species and habitats. Despite the widespread adoption of such conservation policies, biodiversity continues to decline (Rands et al. 2010) and current extinction rates are about 1000 times the expected background rate (Pimm et al. 2014). The effectiveness of the $\mathrm{CBD}$ and other such policy instruments are dependent on a range of factors, including country-specific constraints such as funding, government involvement, social capital, ecosystems and ecosystem services, and multiple other factors that drive conservation policy (Martín-López et al. 2009). Even so, having the best available science to inform policy development and environmental decision making is assumed to be beneficial. However, widespread data deficiencies (Bland et al. 2015) and conservation research biases (Clark and May 2002) exist. Conservation efforts can improve the status of the world's vertebrates (Hoffman et al. 2010), but less is known about invertebrates, likely due, in part, to data deficiencies and practical considerations such as lack of funding and technical limitations. While greater research on threatened species cannot ensure their protection, understanding taxonomic bias may be helpful in order to address knowledge gaps and inform policy. 
Using data for over 10000 threatened animal species, we investigated taxonomic and geographic biodiversity conservation research trends worldwide. We interpret these results in the context of refocusing conservation research priorities to fill critical data gaps and effect policy change. With concerns that understudied species may have higher risk of imperilment and extinction (McKinney 1999), there is a need to identify key knowledge gaps and biases to inform and enhance biodiversity conservation policies and actions and to provide a path forward for effective policy development.

\section{Methods}

We created a database of all animal species listed as critically endangered, endangered, or vulnerable on the International Union for Conservation of Nature (IUCN) Red List (IUCN Red List of Threatened Species 2012). Our search returned 10615 animal species; 7227 vertebrates from the taxonomic groups Mammalia, fish classes (including Actinopterygii, Cephalaspidomorphi, Chondricthyes, Myxin, and Sacropterygii), Reptilia, Aves, and Amphibia; as well as 3388 invertebrates from the taxonomic groups Cnidaria (including Anthozoa and Hydrozoa), Crustacea, Insecta, other invertebrates (including Arachnida, Chilopoda, Diplopoda, Enopla, Onychophora, Polychaeta, and Clitellata), and Mollusca (including Bivalvia and Gastropoda).

We searched the Web of Science (WoS) citation indexing database (Thomson Reuters 2012) and tallied the number of papers on each species (Fig. 1). The most recent nomenclature for the species, as cataloged in the IUCN Red List, was used to search WoS, so previous species name changes may not have been captured in this search. To determine the number of biodiversity conservation-themed papers, we refined our search by the WoS "biodiversity conservation" subject field, in order to capture papers relevant to the fields of biodiversity and conservation (Fig. 2). We then recorded the number of papers published for threatened vertebrate and invertebrate species native to each ocean or continent (Fig. 3a). To account for variation in the number of species assessed by the IUCN Red List in

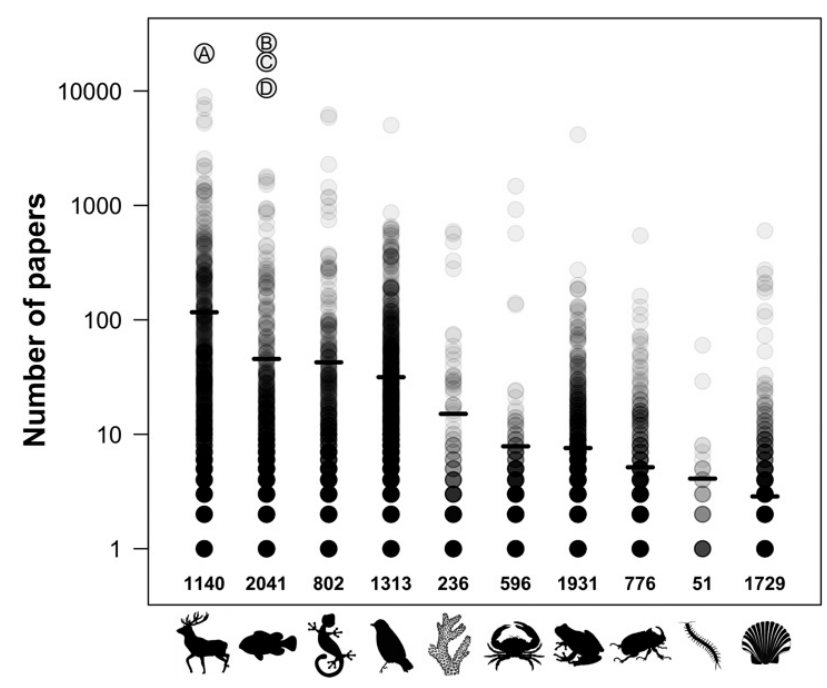

FACETS | 2016 | I: 105-II3 | DOI: 10.1139/facets-2016-00 I | facetsjournal.com
Fig. 1. Number of papers published on each animal taxa, including (from left to right along $x$-axis): Mammalia, fish (including Actinopterygii, Cephalaspidomorphi, Chondricthyes, Myxin, and Sacropterygii), Reptilia, Aves, Cnidaria (including Anthozoa and Hydrozoa), Crustacea, Amphibia, Insecta, other invertebrates (including Arachnida, Chilopoda, Diplopoda, Enopla, Onychophora, Polychaeta, and Clitellata), and Mollusca (including Bivalvia and Gastropoda). Means are represented by horizontal bars, and data are plotted on a log-transformed $y$-axis. Increasingly transparent data points indicate a lower density of clustered data. The total number of species examined for each taxa is indicated above the $x$-axis. Letters represent species with a high number of papers published on (A) tiger Panthera tigris; (B) European eel Anguilla anguilla; (C) common carp Cyprinus carpio; (D) Atlantic cod Gadus morhua. 


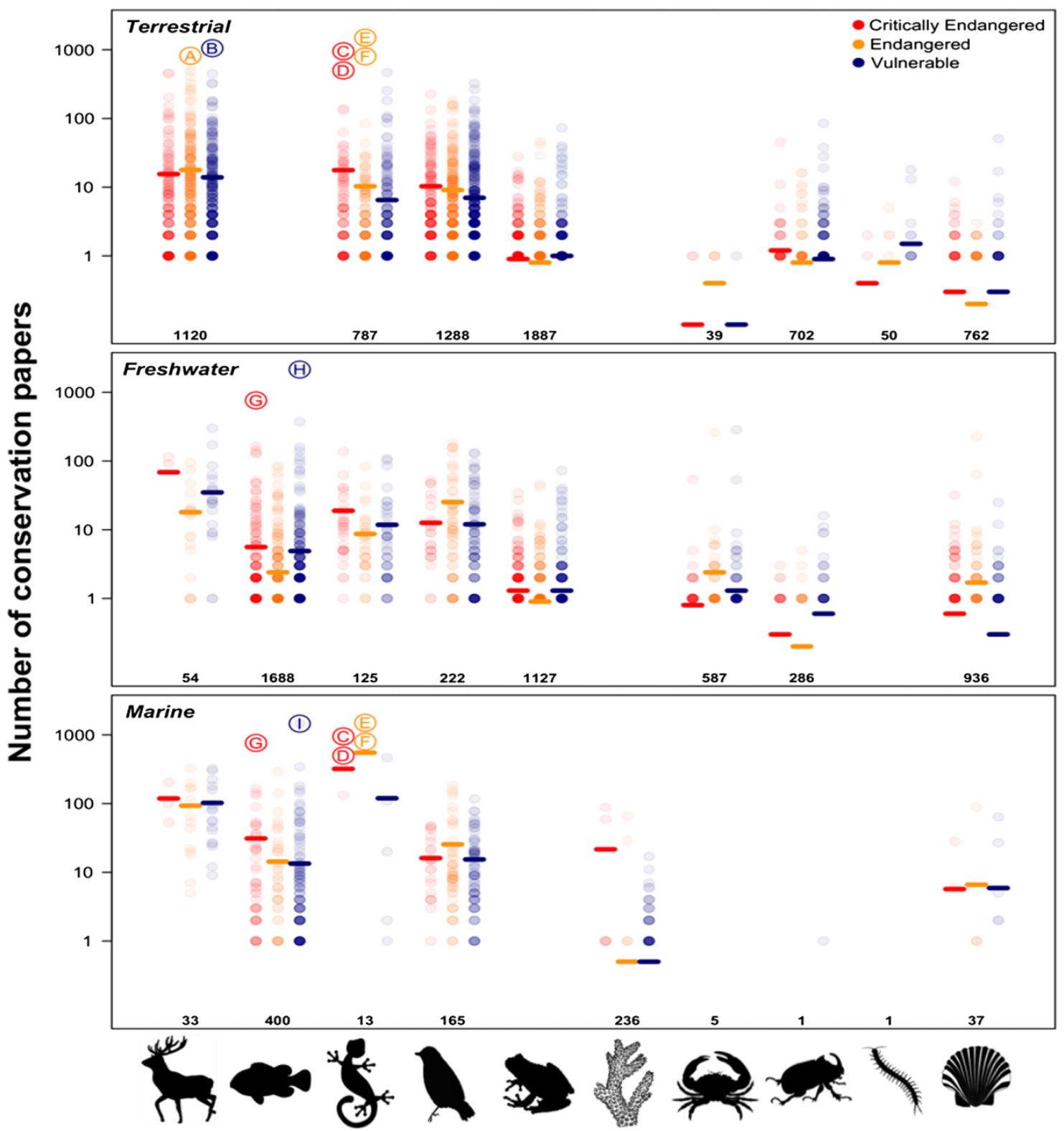

Fig. 2. Number of biodiversity conservation papers published on each animal taxa listed as critically endangered, endangered, or vulnerable on the International Union for the Conservation of Nature Red List in terrestrial, freshwater, and marine habitats. Taxa listed from left to right along the $x$-axis include the following: Mammalia, fish (including Actinopterygii, Cephalaspidomorphi, Chondricthyes, Myxin, and Sacropterygii), Reptilia, Aves, Cnidaria (including Anthozoa and Hydrozoa), Crustacea, Amphibia, Insecta, other invertebrates (including Arachnida, Chilopoda, Diplopoda, Enopla, Onychophora, Polychaeta, and Clitellata), and Mollusca (including Bivalvia and Gastropoda). Means are represented by horizontal bars, and data are plotted on a log-transformed $y$-axis. Increasingly transparent data points indicate a lower density of clustered data. The total number of species examined for each taxa within each threat category is indicated above the $x$-axis. Letters represent species with a high number of papers published on (A) tiger Panthera tigris; (B) African bush elephant Loxodonta africana; (C) leatherback sea turtle Dermochelys coriacea; (D) hawksbill sea turtle Eretmochelys imbricata; (E) green sea turtle Chelonia mydas; (F) loggerhead sea turtle Caretta caretta; (G) European eel Anguilla anguilla; (H) common carp Cyprinus carpio; (I) Atlantic cod Gadus morhua. 
each location, we calculated the ratio of biodiversity conservation papers to species listed as critically endangered, endangered, or vulnerable on the IUCN Red List in each location (Fig. $3 b$ ). Locations included the following terrestrial, freshwater, and ocean habitats: Africa, Antarctic, Arctic Sea, Asia, Atlantic Ocean, Caribbean Islands, Europe, Indian Ocean, Mediterranean and Black Sea, Mesoamerica, North America, Oceania, Pacific Ocean, and South America.

The IUCN Red List 2012 catalogs possible threats affecting each species on the Red List. We recorded each threat in our database and present the threats affecting vertebrates and invertebrates using the thickness of the connecting lines to illustrate the proportion of species affected by each threat (Fig. 4).

\section{Results and discussion}

\section{Taxonomic trends}

The criticisms that biodiversity indicators used by policymakers operating under international agreements are underdeveloped and lack sufficient data (Walpole et al. 2009) are magnified for understudied taxa. In general, charismatic animals tend to receive the most attention from the general public (Genovart et al. 2013) and conservation scientists (Bonnet et al. 2002; Lawler et al. 2006). Our analysis revealed large differences among groups in numbers of biodiversity conservation papers published per

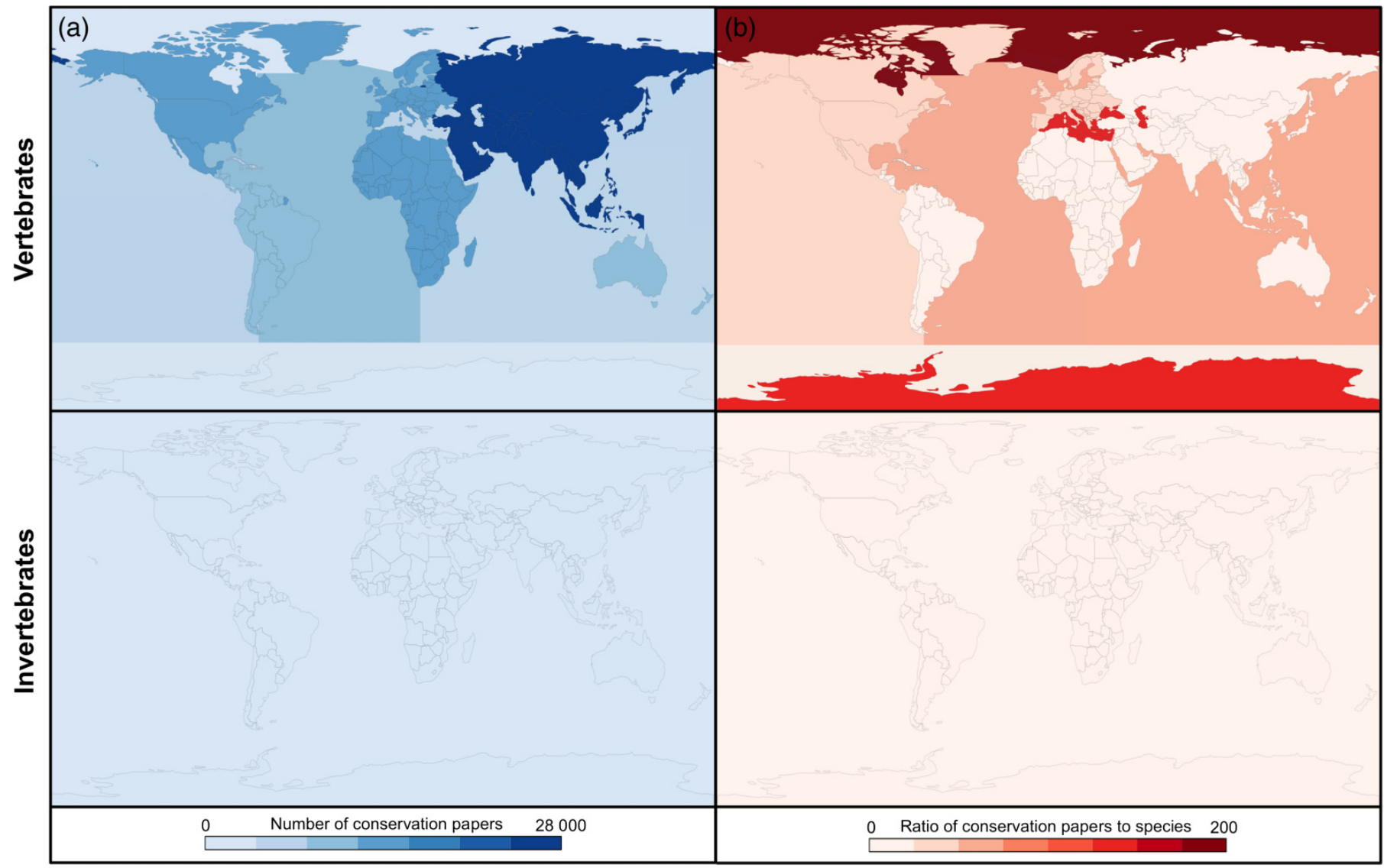

Fig. 3. (a) Total number of published biodiversity conservation papers for threatened vertebrate and invertebrate species native to each ocean or continent. (b) To account for species distributions, the ratio of published biodiversity conservation papers to species for threatened vertebrate and invertebrate species native to each ocean or continent was calculated. 


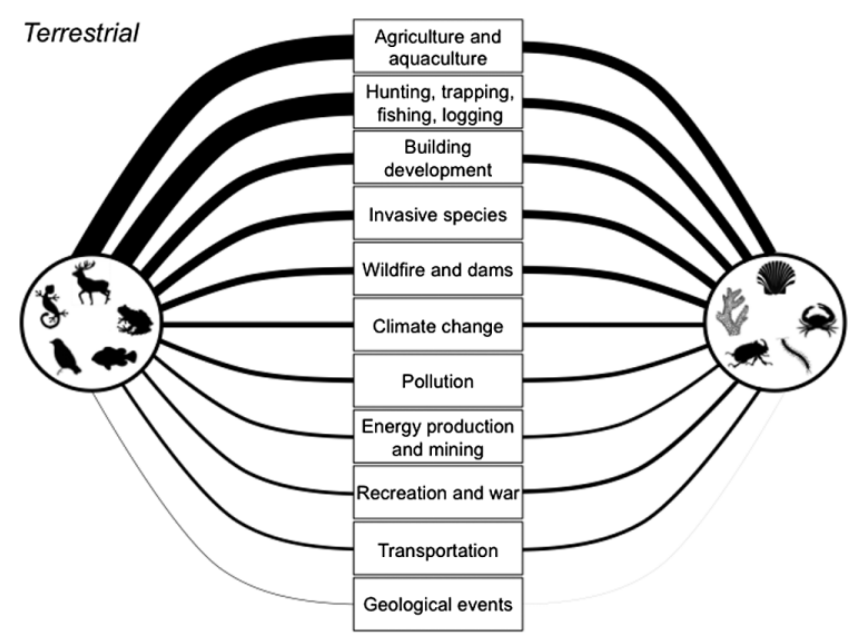

Fig. 4. Threats affecting threatened vertebrate and invertebrate species. Line thickness represents the number of species affected by each threat relative to the total number of vertebrate or invertebrate species. Figure 1 shows the legend for each taxonomic grouping.
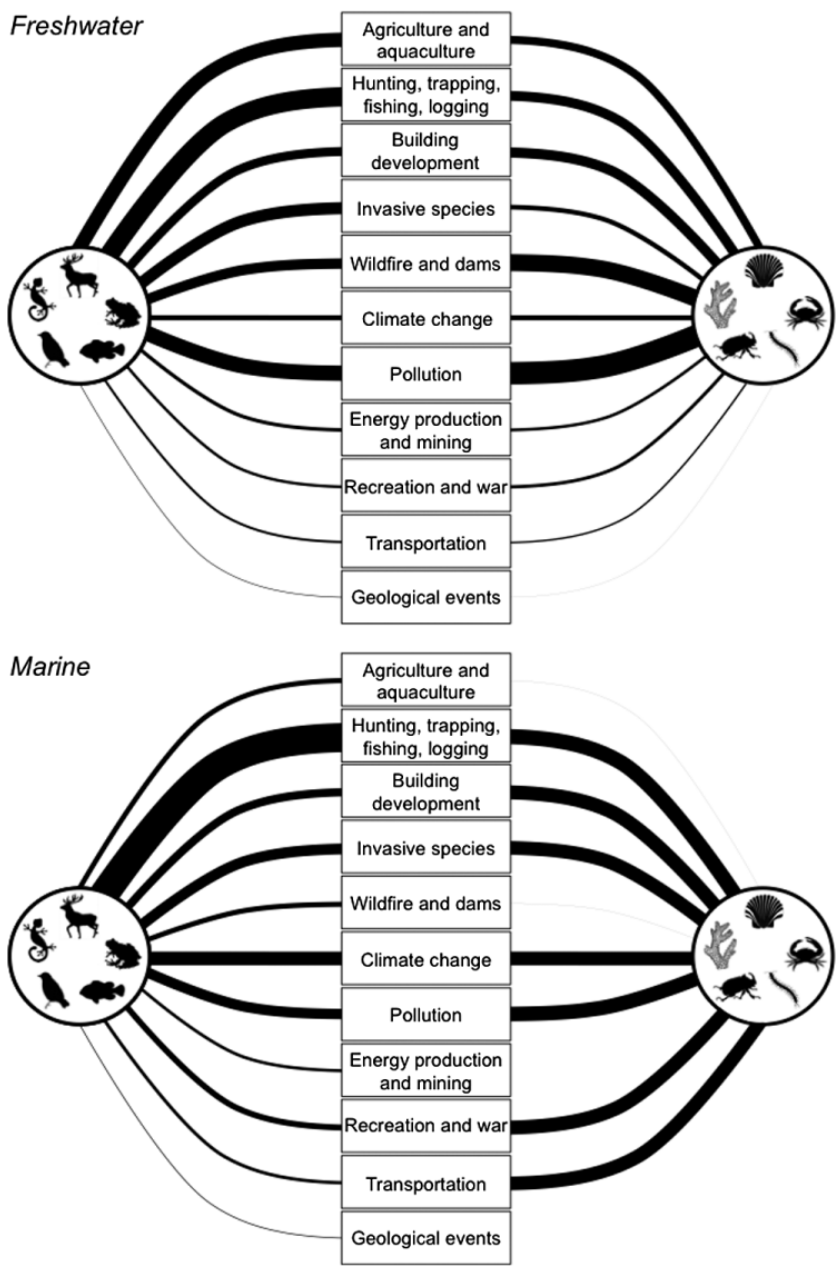
species listed on the IUCN Red List (mammals: 17.1, reptiles: 9.8, birds: 8.2, fishes: 5.9, amphibians: 0.9, and all invertebrates: 0.9; Fig. 1).

Certain mammal (e.g., tiger Panthera tigris Linnaeus, African bush elephant Loxodonta africana Blumenbach), fish (e.g., Atlantic cod Gadus morhua Linnaeus, common carp Cyprinus carpio Linnaeus; which have been introduced to many locations outside their native ranges, European eel Anguilla anguilla Linnaeus), and reptile species (e.g., leatherback Dermochelys coriacea Vandelli, hawksbill Eretmochelys imbricata Linnaeus, and green sea turtles Chelonia mydas Linnaeus) were the focus of more than 600 biodiversity conservation papers each, and emerged as outliers compared with other threatened species. Common carp, in particular, have been studied in a conservation context, not due to their declining population, but rather due to the fact that they have been introduced elsewhere and may have affected other native populations. However, even with these outliers removed, vertebrate taxa still had much higher biodiversity conservation papers published per species (mammals: 15.5, reptiles: 5.2, fish: 3.7). No invertebrate species emerged as outliers (all species had $<300$ papers). Although encouraging reports suggest that conservation efforts can improve the status of the world's vertebrates (Hoffman et al. 2010), less is known about invertebrates. In fact, even in the IUCN Red List, the majority of invertebrate species remain not evaluated (IUCN Red List of Threatened Species 2012). Compared with invertebrates, we found that vertebrates had 12.3, 5.3, and 13.5-fold more biodiversity conservation papers published per species in terrestrial, freshwater, and marine habitats, respectively (Fig. 2). Such bias in conservation research has implications for scientific study, funding, and policy (Trimble and Van Aarde 2010) and raises new concerns for threatened invertebrates worldwide.

\section{Geographic trends}

Our analysis revealed that in all regions, the number of biodiversity conservation papers published on threatened invertebrates was considerably lower and less variable compared with threatened vertebrates in terrestrial, freshwater, and ocean habitats (Fig. 3). Specifically, our analysis revealed that a higher number of threatened species are native to terrestrial and freshwater habitats (11 547) compared with ocean habitat (1046). Ultimately, this result suggests that nearly all invertebrate assessments of threat status are determined using limited scientific information regardless of geographic location, whereas the quantity of information used to assess vertebrates is much greater and more variable. For example, there are large biases to conservation papers studying vertebrates in the Arctic Ocean (200.0) and Mediterranean and Black Sea (140.5).

\section{Focus on common threats}

We provide evidence for extreme bias in conservation research effort on threatened vertebrates compared with lesser-studied invertebrates in both terrestrial and aquatic habitats at a global scale. Research biases may have implications for our relative understanding of threatened species (Pawar 2003) and conservation prioritization (Hoffman et al. 2010), but also have important implications for research funding (Darwall et al. 2011) and international decision-making and policy (MartínLópez et al. 2009). Although these discrepancies are not easily rectified, there may be opportunities to refocus research objectives and international policy development based on common threats (Fig. 4). We found that the threats facing well-studied vertebrates and poorly studied invertebrates tend to be proportionally similar in terrestrial and freshwater habitats. Threats in terrestrial habitats (e.g., agricultural activities, natural resource use, and habitat alteration) are proportionally similar for both vertebrate and invertebrate species. Likewise, the most prevalent threats for freshwater vertebrates (e.g., pollution, habitat modifications such as dams) are proportionally similar for freshwater invertebrates. Despite comparable threats among taxa in terrestrial and freshwater habitats, in marine habitats, threats affecting invertebrates differ considerably from those affecting vertebrates 
(Fig. 4; Mengerink et al. 2014). These differences must be accounted for in the design of marine protected areas (PAs) to effectively protect threatened vertebrates and invertebrates to meet global conservation targets (Le Saout et al. 2013).

Networks of PAs, developed to conserve at-risk plants and animals, are expanding worldwide and comprise more than $12 \%$ of the global land surface and nearly $1 \%$ of the oceans (Sutherland et al. 2009). International agreements, such as the United Nations CBD and World Heritage Convention, provide global frameworks for guiding the establishment and management of PAs. Yet, the effectiveness of PAs depends, at least in part, on the quality and quantity of the scientific research that is available on the at-risk species that PAs aim to protect. PAs are often established in high biodiversity regions to protect multiple species (Le Saout et al. 2013), but few PAs are established with the goal of protecting invertebrates specifically. Further complicating conservation efforts, analysis of species declines, and conservation efforts typically occur at large geographic scales, whereas analysis of recovery often focuses on specific species, populations, and regions (Hutchings et al. 2012).

An encouraging method of starting to redress taxonomic bias in conservation science is to better utilize citizen science, through crowd-sourced data and online databases, which offer continually increasing accessibility and knowledge-sharing opportunities (Pimm et al. 2014). Citizen science activities focused on invertebrates (e.g., e-butterfly.org, bumblebeewatch.org) have garnered considerable public interest and resulted in the collection of a large quantity of data in a short amount of time. Such observations, after evaluation of their reliability, can contribute to peer-reviewed research and supplement existing online databases to provide information on natural history, ecology, population trends, and estimates of geographic ranges, even for understudied taxa. That information can then be incorporated into integrative frameworks (Dawson et al. 2011) to better predict how threatened taxa may be affected by different threats. Whether data are collected through citizen science programs or traditional research programs, prioritization must occur for target species based on criteria such as availability of taxonomic expertise and likely ecological importance (Gerlach et al. 2014).

Addressing taxonomic biases alone may not result in direct conservation actions, but understanding these biases may become increasingly valuable given the likelihood of taxa- (Root et al. 2003) and region-specific (Hampe and Petit 2005) differences in how animals respond to global change. Considering that taxonomic biases can influence how we measure global change (Balmford et al. 2003), there is a need for better integration of conservation-focused research efforts at a global scale to ensure that we improve our understanding of threatened animals, particularly understudied invertebrates. This knowledge may be increasingly valuable given the recent evidence that biodiversity loss itself may exacerbate global change (Sutherland et al. 2013). Narrowing the research gap between vertebrates and invertebrates may facilitate more effective conservation policies to limit biodiversity declines (Waldron et al. 2013).

\section{Acknowledgements}

MRD was supported by a Natural Sciences and Engineering Research Council of Canada postdoctoral fellowship.

\section{Author contributions}

Conceived and designed the study: MRD, NJB, DCB, CDS, SGH, SJC, JTK. Performed the experiments/collected the data: MRD, NJB, DCB. Analyzed and interpreted the data: MRD, NJB, DCB, CDS, SGH, SJC, JTK. Contributed resources: MRD, NJB, DCB, CDS, SGH, SJC, JTK. Drafted or revised the manuscript: MRD, NJB, DCB, CDS, SGH, SJC, JTK. 


\section{Competing interests}

SJC is currently serving as a Subject Editor for FACETS, and MRD is employed by Canadian Science Publishing but neither was involved in review or editorial decisions regarding this manuscript.

\section{Data accessibility statement}

All relevant data are within the paper.

\section{References}

Balmford A, Green RE, and Jenkins M. 2003. Measuring the changing state of nature. Trends in Ecology \& Evolution, 18(7): 326-330. doi:10.1016/S0169-5347(03)00067-3.

Bland LM, Collen B, Orme CDL, and Bielby J. 2015. Predicting the conservation status of data-deficient species. Conservation Biology, 29(1): 250-259. doi:10.1111/cobi.12372.

Bonnet X, Shine R, and Lourdais O. 2002. Taxonomic chauvinism. Trends in Ecology \& Evolution, 17(1): 1-3. doi:10.1016/S0169-5347(01)02381-3.

Clark JA, and May RM. 2002. Taxonomic bias in conservation research. Science, 297(5579): 191-192. doi:10.1126/science.297.5579.191b.

Darwall WRT, Holland RA, Smith KG, Allen D, Brooks EGE, Katarya V, et al. 2011. Implications of bias in conservation research and investment for freshwater species. Conservation Letters, 4(6): 474-482. doi:10.1111/j.1755-263X.2011.00202.x.

Dawson TP, Jackson ST, House JI, Prentice IC, and Mace GM. 2011. Beyond predictions: Biodiversity conservation in a changing climate. Science, 332(6025): 53-58. doi:10.1126/science.1200303.

Genovart M, Tavecchia G, Enseñat JJ, and Laiolo P. 2013. Holding up a mirror to the society: Children recognize exotic species much more than local ones. Biological Conservation, 159: 484-489. doi:10.1016/j.biocon.2012.10.028.

Gerlach J, Samways MJ, Hochkirch A, Seddon M, Cardoso P, Clausnitzer V, et al. 2014. Prioritizing non-marine invertebrate taxa for Red Listing. Journal of Insect Conservation, 18(4): 573-586. doi:10.1007/s10841-014-9660-6.

Hampe A, and Petit RJ. 2005. Conserving biodiversity under climate change: The rear edge matters. Ecology Letters, 8(5): 461-467. doi:10.1111/j.1461-0248.2005.00739.x.

Hoffmann M, Hilton-Taylor C, Angulo A, Böhm M, Brooks TM, Butchart SHM, et al. 2010. The impact of conservation on the status of the world's vertebrates. Science, 330(6010): 1503-1509. doi:10.1126/science.1194442.

Hutchings JA, Butchart SHM, Collen B, Schwartz MK, and Waples RS. 2012. Red flags: Correlates of impaired species recovery. Trends in Ecology \& Evolution, 27(10): 542-546. doi:10.1016/j. tree.2012.06.005.

International Union on the Conservation of Nature (IUCN) Red List of Threatened Species. 2012. Version 2012.2. Available from www.iucnredlist.org.

Lawler JJ, Aukema JE, Grant JB, Halpern BS, Kareiva P, Nelson CR, et al. 2006. Conservation science: A 20-year report card. Frontiers in Ecology and the Environment, 4(9): 473-480. doi:10.1890/ 1540-9295(2006)4[473:CSAYRC]2.0.CO;2. 
Le Saout S, Hoffmann M, Shi Y, Hughes A, Bernard C, Brooks TM, et al. 2013. Protected areas and effective biodiversity conservation. Science, 342(6160): 803-805. doi:10.1126/science.1239268.

Martín-López B, Montes C, Ramírez L, and Benayas J. 2009. What drives policy decision-making related to species conservation? Biological Conservation, 142(7): 1370-1380. doi:10.1016/j. biocon.2009.01.030.

McKinney ML. 1999. High rates of extinction and threat in poorly studied taxa. Conservation Biology, 13(6): 1273-1281. doi:10.1046/j.1523-1739.1999.97393.x.

Mengerink KJ, Van Dover CL, Ardron J, Baker M, Escobar-Briones E, Gjerde K, et al. 2014. A call for deep-ocean stewardship. Science, 344(6185): 696-697. doi:10.1126/science.1251458.

Pawar S. 2003. Taxonomic chauvinism and the methodologically challenged. Bioscience, 53(9): 861-864. doi:10.1641/0006-3568(2003)053[0861:tcatmc]2.0.co;2.

Pimm SL, Jenkins CN, Abell R, Brooks TM, Gittleman JL, Joppa LN, et al. 2014. The biodiversity of species and their rates of extinction, distribution, and protection. Science, 344(6187): 987. doi:10.1126/science.1246752.

Rands MRW, Adams WM, Bennun L, Butchart SHM, Clements A, Coomes D, et al. 2010. Biodiversity conservation: Challenges beyond 2010. Science, 329(5997): 1298-1303. doi:10.1126/ science.1189138.

Root TL, Price JT, Hall KR, Schneider SH, Rosenzweig C, and Pounds JA. 2003. Fingerprints of global warming on wild animals and plants. Nature, 421: 57-60. doi:10.1038/nature01333.

Sutherland WJ, Adams WM, Aronson RB, Aveling R, Blackburn TM, Broad S, et al. 2009. One hundred questions of importance to the conservation of global biological diversity. Conservation Biology, 23(3): 557-567. doi:10.1111/j.1523-1739.2009.01212.x.

Sutherland WJ, Aveling R, Brooks TM, Clout M, Dicks LV, Fellman L, et al. 2013. A horizon scan of global conservation issues for 2013. Trends in Ecology \& Evolution, 28(1): 16-22. doi:10.1016/j. tree.2012.10.022.

Thomson Reuters. 2012. Web of Science (WoS) citation indexing database. Available from: http:// www.webofknowledge.com.

Trimble MJ, and Van Aarde RJ. 2010. Species inequality in scientific study. Conservation Biology 24(3): 886-890. doi:10.1111/j.1523-1739.2010.01453.x.

Waldron A, Mooers AO, Miller DC, Nibbelink N, Redding D, Kuhn TS, et al. 2013. Targeting global conservation funding to limit immediate biodiversity declines. Proceedings of the National Academy of Sciences of the United States of America, 110(29): 12144-12148. doi:10.1073/pnas.1221370110.

Walpole M, Almond REA, Besançon C, Butchart SHM, Campbell-Lendrum D, Carr GM, et al. 2009. Tracking progress toward the 2010 biodiversity target and beyond. Science, 325(5947): 1503-1503. doi:10.1126/science.1175466. 